\title{
O FILÓSOFO DA VIDA MODERNA: Baudelaire, Merleau-Ponty e a arte da crítica fenomenológica ${ }^{1}$
}

\section{The philosopher of modern life: Baudelaire, Merleau-Ponty and the art of phenomenological critique}

\author{
Duane H. Davis
}

Professor Titular de Filosofia da Universidade da Carolina do Norte em Asheville. Tradução de Richard Theisen Simanke, Universidade Federal de São Carlos.

Para Cynthia Willet e Tyronne Williams, cujo autêntico espírito crítico [filosófico e poético] continua a servir de inspiração.

\footnotetext{
Trabalho apresentado no VI Congresso de Filosofia Contemporânea, na Pontifícia Universidade Católica do Paraná, Curitiba, Brasil, em 5 de agosto de 2008. Gostaria de agradecer ao Prof. Richard Simanke por ter-se, generosamente, encarregado do projeto de tradução deste artigo, assim como por sua amizade e apoio. Gostaria de agradecer também ao Prof. Ericson Falabretti pela estimulante questão formulada após eu ter apresentado este ensaio no VI Congresso de Filosofia Contemporânea da PUCPR. O Dr. Falabretti observou, corretamente, que se pode ler o "Prefácio" à Fenomenologia da percepção de Merleau-Ponty em apoio à minha sugestão de que a fenomenologia pode ser construída como uma arte, mais do que como uma ciência. Gostaria ainda de agradecer ao Dr. Tyronne Williams [Xavier University of Cincinnati, EUA] e ao Dr. Tony O'Connor [University College, Cork, Irlanda], pois ambos objetaram que eu faço uma falsa oposição entre ciência e arte neste ensaio. Concordo que preferi radicalizar a oposição para produzir uma nova perspectiva. Posso apenas replicar que estou, aqui, seguindo Merleau-Ponty, para o bem ou para o mal, e que o contexto de um paradigma científico dominante requer, hoje, essa estratégia, mesmo que esta não forneça a palavra final sobre o assunto. Na verdade, esperemos que não haja uma palavra final sobre o assunto.
} 


\section{Resumo}

Este artigo se organiza em torno dos eixos da reversibilité e do écart no contexto das críticas antirromânticas da modernidade em Baudelaire e Merleau-Ponty. Mais especificamente, eu proponho as seguintes teses: 1) O realismo antirromântico de Baudelaire possui notáveis paralelos com o pensamento tardio de Merleau-Ponty. 2) A obra tardia de Merleau-Ponty pode ser lida como uma apropriação ontológica do antirromantismo de Baudelaire, no seu desenvolvimento dos conceitos de reversibilité e écart. Por fim, 3) reconhecer os aspectos baudelaireanos do pensamento ontológico de Merleau-Ponty revela seu horizonte crítico (social e político) e tem implicações para nossa própria situação crítica com relação à modernidade.

Palavras-chave: Merleau-Ponty. Baudelaire. Reversibilité. Écart. Correspondências. Crítica fenomenológica.

\section{Abstract}

This paper is organized along the axes of réversibilte and écart in the context of Baudelaire's and Mearleau-Ponty's anti-romantic critiques of modernity. More specifically, I pose the following theses. (1) Baudelaire's anti-romantic realism is a striking parallel to MerleauPonty's later thought. (2) Merleau-Ponty's later work can be read as an ontological appropriation of Baudelaire's anti-romanticism in his development of réversibilté and écart in his later work. Finally, (3) recognizing the Baudelairean aspects of Merleau-Ponty's ontological thought reveals its critical (social and political) horizon and has implications for our own critical situation with respect to modernity.

Keywords: Merleau-Ponty. Baudelaire. Reversibilité. Écart. Correspondences. Phenomenological critique.

Um espectro ronda a Europa - ou, pelo menos, Paris. Foi assim que eu vim a ser apresentado ao Sr. Charles Baudelaire, em 1999². Eu estava trabalhando duro na Biblioteca Nacional em Paris, lendo notas e

2 Charles Baudelaire (1821-1867). 
manuscritos de Merleau-Ponty. Como não sou rico, minhas estadias em Paris são bastante breves, e quase que cada uma das horas de luz do dia precisa ser aproveitada na sala de leitura de manuscritos ocidentais. Numa dessas viagens, no entanto, estava um pouco adiantado com minha programação de trabalho. Durante dez dias, tinha estado lendo as notas de trabalho feitas por Merleau-Ponty para seu ensaio L'Oeil et l'Esprit. Como alguns de vocês devem saber por experiência pessoal, decifrar a caligrafia de Merleau-Ponty é uma tarefa formidável; assim, meus olhos estavam ardendo na hora em que terminei de trabalhar com a seção que eu tinha selecionado. Já que era uma adorável tarde de sexta-feira, já que eu tinha terminado a minha tarefa e já que devia voltar para casa no dia seguinte, decidi ir visitar os boquinistes perto do Sena e dar uma passada num café da Ile St. Louis, um de meus lugares preferidos em Paris.

Como de hábito, depois de atravessar para a ilha pela ponte próxima a Notre-Dame, caminhei sem pressa ao longo dos ancoradouros de ambos os lados da pequena ilha, cumprimentando os dois canais do Sena, antes de me estabelecer num café bem perto da ponte que tinha acabado de atravessar. Aproveitando para relaxar, pedi chá e abri minha pequena sacola de tesouros recém-adquiridos, que incluíam um exemplar barato de Les Fleurs du Mal, de Baudelaire. Abri o livro e comecei a ler avidamente os poemas. Naquele dia, algumas surpresas me estavam reservadas.

Ora, essa estadia em Paris, especificamente, era a última etapa de uma viagem mais longa para vários lugares da Europa - como sempre, combinadas para maximizar as oportunidades oferecidas pelo (para mim) dispendioso voo transcontinental. Eu já tinha ido à Itália e ao País de Gales para proferir palestras em congressos, antes de vir a Paris para revisitar os manuscritos de Merleau-Ponty. Assim, estava havia cinco semanas longe da família, cansado e um pouco solitário. Talvez esse não seja o melhor estado de espírito para ler Baudelaire, que pode ser, às vezes, um pouco deprimente. De fato, ele tem um jeito todo seu de mostrar que tudo tem um lado tenebroso. Passado algum tempo, abandonei momentaneamente os poemas sombrios para ler a informação biográfica incluída no prefácio. Foi então que me dei conta de que tinha acabado de passar em frente a seu antigo lar, no Hôtel Pimodan. E, naquele momento, estava sentado bem na rua de onde ele costumava ir visitar a infame Jeanne Duval, que inspirou muitos de seus poemas. Quantas vezes não teria Baudelaire andado de um lado para o outro sobre as pedras dessa rua? 
Um arrepio desceu-me pela espinha. Fiquei espantado com a coincidência! De todos os livros que eu pudesse ter comprado e de todos os lugares que pudesse ter escolhido para sentar e ler - era como se o espírito de Baudelaire tivesse vindo à biblioteca e lá me convocado para sua casa, seu retiro, sua musa. Mas, então, o que quereria ele me mostrar?

Lembrei-me de que Merleau-Ponty tinha dedicado um de seus primeiros cursos em Lyon às obras de Proust e Baudelaire. É claro, Mauro Carbone e Len Lawlor, entre outros, tinham, com razão, devotado sérios estudos às conexões entre Merleau-Ponty e Proust ${ }^{3}$. Obviamente, a obra publicada de Merleau-Ponty está saturada de referências a Proust, oblíquas ou diretas. Em sua obra póstuma, Le visible et l'invisible, Merleau-Ponty chega a afirmar que "ninguém foi mais longe do que Proust na fixação das relações entre o visível e o invisível" (MERLEAU-PONTY, 1964, p. 195) ${ }^{4}$. E qualquer um que tenha apenas passado os olhos pelas notas não publicadas de Merleau-Ponty terá visto que ele é inspirado por Proust ao longo da maior parte da sua carreira, em um grau ainda maior do que suas publicações indicam 5 .

Mas chega de Proust por ora: o que terá acontecido com a influência de Baudelaire? Talvez o espírito de Baudelaire estivesse me mostrando a resposta para essa pergunta. Retornei aos poemas com renovado interesse! E, vejam só, lá estava o poema intitulado Reversibilité ${ }^{6}$. Esses fantásticos poemas estavam fervilhando com tantas das metáforas que animam os escritos ontológicos de Merleau-Ponty em sua obra mais tardia.

Meu tema hoje é invocar o espírito baudelairiano que ronda o pensamento de Merleau-Ponty, chamá-lo para que se revele e saia para a luz. Isso tem certa importância intrínseca, uma vez que a crítica da modernidade de Baudelaire revela profundidade no trabalho de MerleauPonty, o qual recebeu muito pouca atenção - um horizonte sociopolítico

3 Len Lawlor tem feito um trabalho destacado sobre os diferentes tipos de amor em Proust e suas manifestações no pensamento de Merleau-Ponty. Cf. também Carbone (2001), que demonstra brilhantemente como a atitude fenomenológica de Merleau-Ponty [como este afirma explicitamente no prefácio a Phénomenologie de la perception] é uma atitude de perplexidade diante do mundo e como o interesse de Merleau-Ponty pelos artistas modernos - especialmente Proust - tem a ver com a atitude similar de perplexidade do artista ao cultivar a latência do sentido para além do visível, para além do literal, sem apelar para um momento de interioridade - "o colapso da noção tradicional de sujeito" (CARBONE, 2001, p. 130).

4 Terei mais a dizer a respeito dessa passagem na segunda seção deste ensaio.

5 É interessante também que todas as vezes em que eu visitei Mme. Merleau-Ponty, ela tivesse um exemplar de algum periódico de estudos a respeito de Proust sobre a mesa.

6 Reversibilité é um dos conceitos centrais na ontologia tardia de Merleau-Ponty. 
da obra tardia de Merleau-Ponty - e mostra como nós poderíamos, hoje, levar essa obra um pouco mais adiante. A imensa questão filosófica que nos espreita despercebida é: qual papel ou papéis filósofos e poetas desempenham na crítica da modernidade?

Esses dois grandes pensadores estiveram separados por cerca de 100 anos, assim como por suas respectivas disciplinas. Organizaremos nossa restrita investigação ao longo dos eixos da reversibilité e do écart [na verdade, correspondances em Baudelaire] no contexto de suas críticas antirromânticas da modernidade. Mais especificamente, eu proponho as seguintes teses: 1) O realismo antirromântico de Baudelaire possui notáveis paralelos com o pensamento tardio de Merleau-Ponty; 2) A obra tardia de Merleau-Ponty pode ser lida como uma apropriação ontológica do antirromantismo de Baudelaire, no seu desenvolvimento dos conceitos de reversibilité e écart; por fim, 3) reconhecer os aspectos baudelairianos do pensamento ontológico de Merleau-Ponty revela seu horizonte crítico (social e político) e tem implicações para nossa própria situação crítica com relação à modernidade.

\section{A "Alquimia do Sofrimento" e a arte da "Ciência Secreta"}

Moesta et errabunda ${ }^{7}$ é mais do que o título de um dos poemas de Baudelaire - ele descreve tanto seu próprio papel angustiado como um poeta na vida urbana moderna quanto sua visão da condição existencial da Europa do século XIX ${ }^{8}$. Sua tristeza pelo estado decadente e condenado da sociedade moderna brota de cada página - suas palavras emergindo em torrentes lacrimejantes de raiva e amor. Baudelaire vagava por Paris como vagava por grande parte da sua vida - impelido a capturar em seu versejar

7 Charles Baudelaire, Les fleurs du mal, poema 62, edição de 1861. Citarei Baudelaire a partir da edição bilíngue, que inclui a tradução de James McGowan. Entretanto, tal como ocorre com todos os textos citados neste ensaio, todas as traduções são minhas, a não ser quando indicado. McGowan é mais sensível à estrutura poética e à rima do que eu prefiro aqui. Para uma apropriação filosófica do trabalho de Baudelaire, considero que uma ênfase maior deva ser colocada sobre o sentido do texto, embora conservando as metáforas originais sempre que possível (BAUDELAIRE, 1993, p. 128). Essa obra, The flowers of evil [acompanhado do texto francês; trad. MacGowan], de Baudelaire, será citada com o número do poema da edição de 1861. "Moesta et errabunda " significa "tristonha e errante".

8 Seria interessante contrastar essa condição errante com a descrição esperançosa de Marcel da condição humana como Homo Viator. 
angustiado a alienação que via e sentia tão profundamente, lamentando a doença de que sofria sua sociedade e que destruía a sua vida e tantas outras. Ao passarmos assoviando pelo cemitério, estamos confiantes em nossas realizações, enquanto permanecemos obcecados por nossas insignificantes tarefas: "despenderemos nossa alma em esquemas sutis" (BAUDELAIRE, 1993, p. 278) ${ }^{9}$. Nossa condição é tão desgraçada que sequer podemos recorrer a Deus em busca de auxílio para lidar com aquilo que forjamos: "Ó Satã, tende piedade de minha longa miséria" (BAUDELAIRE, 1993, p. 268) ${ }^{10}$. No entanto, o amor, em Baudelaire, expressava-se tão apaixonadamente quanto sua cáustica repugnância. $\mathrm{O}$ orgulho por suas habilidades aparece em seu papel como poeta e, mais uma vez, reflete também uma condição existencial; pois, segundo ele, nós devemos amar, até o ponto em que o amor permanece possível. Talvez nunca tenha havido um testemunho mais profundo e complexo de alienação, tédio e repugnância diante da condição humana moderna.

Sofremos da vida moderna que infligimos a nós mesmos. Mas talvez Baudelaire mostre que a expressão de nosso sofrimento tenha um efeito transformativo, por mais que esta seja distinta da autopiedade romântica de Shelley ou Byron. Ou, pelo menos, ele superou essa espécie de amor romântico por si mesmo. Baudelaire mostra-se claramente impressionado por suas próprias habilidades - quer estas tenham ou não sido suficientemente reconhecidas por sua mãe, seu meio-irmão, seus professores, seus colegas, o conselheiro legal e financeiro de sua família, seus editores, seus críticos ou seus leitores ${ }^{11}$. Mas ele também sente

9 BAUDELAIRE, "La mort des artistes" (1993, p. 278, poema 23): "Nous userons notre âme en de subtils complots".

10 BAUDELAIRE (1993, p. 268): Esse é o refrão do poema “Litanias de Satã” (poema 120): “Ô Satan, prends pitié de ma longue misère".

11 O relacionamento de Baudelaire com sua mãe aparece muito na literatura secundária. Seu pai faleceu quando ele tinha apenas 5 anos de idade, e sua mãe casou-se novamente já no ano seguinte. Baudelaire odiou o padrasto por toda sua vida e nunca perdoou a mãe por ter-se casado de novo, muito embora ela se tivesse casado com um homem muito bem-sucedido. É consenso geral que Baudelaire considerava que seu amor pela mãe deveria ter-lhe sido suficiente. Ao mesmo tempo, ela era extremamente possessiva com relação a ele, recusando-se a pôr-lhe limites, contra o conselho de seu novo marido, de seu enteado e dos consultores familiares. Por volta de 1844 , ele estava gastando sua herança num ritmo irracional, e ela foi persuadida a restringir-lhe o acesso a esses fundos. Não obstante esse ato disciplinar, ela continuou superprotegendo seu garoto, mesmo quando ele foi envelhecendo, ao que ele reagiu tornando-se cada vez mais autodestrutivo. Cf. qualquer das muitas biografias de Baudelaire, tais como: Joanna Richardson (1994, p. 3-219); Enid Starkie (1958, p. 27-83); os trabalhos de Jean-Paul Sartre sobre Baudelaire, etc. 
desprezo por suas próprias limitações, suas aflições autoimpostas, seus vícios, doenças, pobreza e sua perpétua penúria pessoal e profissional. E essa dimensão inspira um poderoso realismo antirromântico em seu trabalho. Baudelaire, tendo desempenhado o papel de dândi até que seus fundos foram cortados, foi sempre também atraído pelo sórdido submundo da Paris urbana - prostituição, vício, pobreza, e o escárnio da moralidade convencional. Ele considerava a moralidade tradicional como uma hipocrisia confortável, mas também deplorava a vida do vício tanto quanto a aceitação ingênua da virtude. Recomendo-lhes qualquer uma das muitas biografias que, com frequência, variam desenfreadamente em suas conclusões especulativas. Baudelaire é apresentado de todas as maneiras, desde como um delinquente burguês até como um satanista perturbado pelas drogas ou como um moralista austero. Cada uma dessas visões possui um grão de verdade, embora nenhuma capture exaustivamente seu caráter.

Voltemos nossa atenção dessas questões biográficas gerais para as implicações filosóficas de dois notáveis poemas de Le Fleurs du Mal que eu acredito tipificarem o estilo do realismo antirromântico de uma parte da obra de Baudelaire, o qual iria, depois, influenciar Merleau-Ponty: Correspondances e Reversibilité ${ }^{12}$. Ler esses poemas por suas implicações filosóficas é menos tendencioso do que certas apropriações filosóficas da poesia, já que Baudelaire, aparentemente, tinha noção também dessas implicações. De acordo com Enid Starkie, Baudelaire teria dito, em algum ponto de sua carreira, que "a filosofia lhe parecia agora a única coisa digna da atenção de um poeta" (STARKIE, 1958, p. 225) ${ }^{13}$.

12 Anexei esses dois poemas e minhas traduções muito literais como um apêndice a este ensaio [Acrescentei uma versão em português, também literal, traduzida por mim (N. T)].

13 Não obstante, ela deduz daí que isso reflete uma virada em direção a um espiritualismo místico, como evidência do amadurecimento de Baudelaire. Não me sinto muito convencido por essa linha de argumentação, como ficará claro num instante. 
Correspondances é um poema vigoroso, que reage tanto ao idealismo de Platão quanto ao misticismo de Swedenborg ${ }^{14}$. Para Baudelaire, quaisquer correspondências que possa haver na vida, que lhe confiram seu sentido e valor, não são aquelas entre um particular e um ideal metafísico, nem tampouco as que dizem respeito a uma simbolização perfeita. O visível não é uma abertura simbólica imperfeita sobre um invisível infinito, perfeito e ideal. Sua relação não é harmônica e simétrica - algum ideal disfarçado, oculto para muitos, mas revelado ao místico. Baudelaire deleitava-se com imagens chocantes e grotescas em sua poesia, que são deliciosos exemplos de dissonância, e não de harmonia. Para Baudelaire, o mundo produz "uma irresistível fascinação pelo horrível" (BAUDELAIRE, 2002, p. 10). Ele afirmou que, para os seres humanos, "o único e supremo deleite reside na certeza de fazer o mal" (BAUDELAIRE apud RICHARDSON, 1994, p. 50). Essas palavras não evidenciam nenhuma harmonia mística, nenhuma ordem moral do mundo, e nenhum idealismo romântico.

Para Baudelaire, correspondências não são simples representações de ideais. Ao contrário, é uma questão de compromisso e contingência, na qual o valor aparece. As correspondências são frequentemente consumadas por meio de justaposições chocantes e

14 Eu gosto mais da interpretação que Jonathan Culler dá a esse poema do que da interpretação de Starkie, pois acho que esta última deixa de perceber a ironia (CULLER, 1990). Para a interpretação oposta, há a leitura que Starkie faz desse poema, como pressagiando a transformação posterior de Baudelaire num moralista espiritual, sob a influência direta de Swedenborg - embora ela faça uma defesa da familiarização gradual de Baudelaire com o misticismo simbólico de Swedenborg desde o seu trabalho sobre Poe (STARKIE, 1958, p. 225-238). Embora eu não seja um especialista nisso, parece-me que Starkie está projetando suas próprias preferências pelos poemas mais tardios de Baudelaire sobre a sua obra inicial, de tal modo que esta última ou manifesta uma gradual familiaridade com a espiritualidade de Swedenborg ou, então, é proto-swedenborgiana. Porém, muitos estudos suplementares seriam necessários para sustentar essa asserção. De fato, as correspondências entre os sentidos parecem ser, com igual probabilidade, tanto um produto das experiências de Baudelaire com haxixe, quanto com a teologia de Swedenborg. Cf. Charles Baudelaire (2002, p. 21): "Objetos externos assumem aparências monstruosas. Eles se revelam a você em formas até agora desconhecidas. Tornam-se, então, distorcidos, transformados e, finalmente, penetram em seu próprio ser, ou você penetra no deles. As mais estranhas equivocações, as mais inexplicáveis transposições de ideias têm lugar. Os sons têm sua própria cor, as cores fazem música. As notas musicais são números... Você está sentado, fumando; você pensa que está sentado em seu cachimbo, e é você que seu cachimbo está fumando; é você mesmo que você está expelindo, na forma de nuvens tingidas de azul". É claro que experiências com haxixe e Swedenborg não precisam ser mutuamente exclusivos. 
vigorosas, que revelam uma perturbadora existência intramundana. Mauro Carbone descreve-o muito bem:

[As correspondências são] a repetição de uma situação já vivida, a relação que é espontaneamente estabelecida entre experiências diferentes e análogas, o agrupamento de coisas, seres ou signos que reenviam [renvoient] a outras coisas, a outros seres, a outros signos, tudo o que parece dar testemunho de um acordo "pré-objetivo" entre o individual e o sensível... (CARBONE, 2001, p. 42).

Talvez devêssemos acrescentar que esse acordo é "présubjetivo", tanto quanto "pré-objetivo", e que é um acordo dinâmico e frágil. Infelizmente, também, o foco de Carbone, nesse trabalho, recai quase que exclusivamente sobre as correspondências em Proust, muito embora ele reconheça, numas poucas palavras imediatamente anteriores a essa passagem, que "pode-se também encontrá[-las] em Baudelaire" (CARBONE, 2001, p. 42). Para ser justo, Carbone está aqui seguindo a orientação explícita de Merleau-Ponty, numa passagem à qual eu me referi anteriormente:

Ninguém foi mais longe do que Proust na fixação das relações entre o visível e o invisível, na descrição de uma idéia que não é o contrário do sensível, que é o seu duplo e a sua profundidade (MERLEAU-PONTY, 1964, p. 195).

Se Proust foi mais longe que qualquer um, sua inspiração - e, daí, a de Merleau-Ponty - pode ser encontrada em Baudelaire. Vale a pena dar uma olhada mais de perto em Baudelaire, para ver o que se pode revelar quanto ao pensamento de Merleau-Ponty.

Correspondances começa com o que pode, à primeira vista, parecer uma idealização romântica da natureza: "A natureza é um templo". Entretanto, logo fica claro que os seres humanos são parte do templo - seus "pilares vivos"; eles lhe dão sustentação e, no entanto, dizem coisas estranhas e confusas. Os humanos são descritos como vagando em uma "floresta de símbolos" que, por sua vez, nos observa como símbolos - como iguais. Aparentemente, em Baudelaire, "Sprache spricht" [a linguagem fala] também.

A unidade que emerge nesse poema não está dada, nem é perfeita, mas sim descrita por meio da metáfora dos "ecos" que se ouvem desde muito longe e, por isso, se entretecem e interagem de novas maneiras. A unidade está vinculada a uma aura de dissonância produtiva e é 
imediatamente descrita em termos visuais, como uma claridade que se deve encontrar na escuridão, e não na luz. É nesses termos contingentes que os sentidos se entretecem e interagem - onde "os perfumes, as cores e os sons se [co-]respondem". A interpenetração desses sentidos é expressa no verbo reflexivo se répondre, em vez de répondre: eles respondem juntos - co-respondem - correspondem. A unidade da correspondência é criativa e ativa, e não estática ou dada a priori.

A atividade das correspondências reflete-se também no termo "expansão das coisas infinitas" - onde essas coisas estão em processo de criar e preencher a expansão ou propagação. E o que é infinito a respeito dessas coisas? Nada além da transcendência da sensação encarnada - aromas e visões e sons e toques e sabores - que propiciam deleites arrebatadores ou sofrimentos abomináveis. E, em última instância, é a percepção que funda a relação entre mente e corpo aqui: "Que cantam a exaltação do espírito e dos sentidos". Baudelaire é, em cada detalhe, um poeta do corpo, tanto quanto um poeta "espiritual". É essa abordagem da percepção e de sua primazia que é tão similar ao que Merleau-Ponty iria chamar de fundamento em sua obra inicial e ao que ele, posteriormente, denominaria "o solo do sensível".

Considero que a provocativa noção merleau-pontyana de écart - divergência ou dispersão criada pela divergência - está prefigurada nas correspondências de Baudelaire. Merleau-Ponty inicia o capítulo sobre o quiasma em $O$ visível e o invisível com a sua ubíqua rejeição da dicotomia sujeito/objeto. Pois, tão logo a filosofia comece com uma distinção ontológica radical entre sujeito e objeto, entre interior e exterior, entre reflexão e coincidência, "ela prejulga o que vai descobrir" (MERLEAU-PONTY, 1964, p. 172). Por isso, é necessário começar de novo, de forma a evitar esses préjuízos, que ficaram sedimentados no discurso da filosofia moderna. Em vez de uma ontologia que pressupusesse um princípio de identidade, MerleauPonty começou a desenvolver uma nova orientação para a ontologia, que era baseada em diferenças: diferenciação - divergência - écart. Essa nova orientação para a ontologia enfatizava a imbricação [empiétement] e a interatividade das coisas, sentidos e seres, como um processo de diferenciação bastante semelhante às correspondências de Baudelaire.

É necessário que nos habituemos, nós mesmos, a pensar que todo o visível é moldado no sensível, todo ser tátil está, de algum modo, votado à visibilidade, e que há imbricação e cruzamento, não apenas entre o que é tocado e quem toca, mas também entre o tangível e o visível que está nele incrustado [...] (MERLEAU-PONTY, 1964, p. 177). 
É por meio dessa imbricação e interferência que a unidade do mundo é produzida. É como essa série de diferenças que a identidade emerge - não como uma unidade estática, dada, harmônica, mas como um horizonte implicado de diferenciação. De fato, o mundo mundifica como um horizonte implicado de diferenciação de horizontes de diferenças.

[Vê-se que], em geral, um visível não é um pedaço de ser absolutamente rígido, indivisível, que se oferece inteiramente desnudado a uma visão que poderia ser apenas total ou nula, mas, antes, é uma espécie de estreito que se abre entre horizontes exteriores e horizontes interiores, algo que vem a tocar de leve e fazer ressoar à distância diversas regiões do mundo colorido ou visível, certa diferenciação [...], a diferença entre coisas e cores, uma cristalização momentânea do ser colorido ou da visibilidade (MERLEAU-PONTY, 1964, p. 175).

Esses estreitos que se abrem consistem no lapso que há entre emergir, desde uma perspectiva, como identidades discretas diferindo uma da outra e, desde outra perspectiva, como o próprio processo de diferenciação. Da mesma forma, uma palavra que enfatiza a diferenciação dessas próprias correspondências baudelairianas na obra tardia de Merleau-Ponty é écart. Mas esta última vai de mãos dadas com a palavra reversibilité, que enfatiza o horizonte de diferenciação - as relações de diferenças. Voltemos nossa atenção para o poema Reversibilité, de Baudelaire, para vermos como ele informa a obra mais tardia de Merleau-Ponty.

Baudelaire escreve esse primoroso poema na voz de um amante que se dirige a outro, a quem ele repetidamente caracteriza como um "anjo". E, embora o anjo seja certamente retratado em termos positivos - isto é, cheio de felicidade, bondade, saúde, beleza, ventura, alegria e luz -, não devemos nos apressar na conclusão de que Baudelaire seja culpado de idealização romântica de sua amada ${ }^{15}$. Há uma grande ironia nesse poema. Uma rápida olhada em outros poemas de Les fleurs du mal mostra-nos que Baudelaire não tem os anjos assim em tão alta estima ${ }^{16}$. Além disso,

15 Martin C. Dillon, em Beyond Romance (State University of New York Press, Albany, 2004), ilustrou brilhantemente os perigos do amor romântico e mostrou como a posição de MerleauPonty pode ser desenvolvida para reconhecer esse problema e evitá-lo. Ele desenvolve essa abordagem, de uma maneira mais geral, no manuscrito que estava terminando na época de sua morte, The Ethics of Particularity.

16 Cf. Les litanies de Satan, onde Satã, é claro, é descrito como um anjo (BAUDELAIRE, 1993, p. 268-273, poema 120). 
fica claro que Baudelaire tem desprezo por alguém que fosse "cheio de felicidade"; no poema anterior a este, À celle qui est trop gaie [Àquela que é feliz demais], Baudelaire fantasia a vivissecção e o estupro de um "anjo" (BAUDELAIRE, 1993, p. 88, poema 43a). Tal pureza de coração é imprópria à condição humana.

O relacionamento é o foco aqui, juntamente com as perspectivas muito divergentes dos amantes envolvidos. Embora o anjo seja feliz, saudável, etc., seu amante a acusa pelos danos que seu semblante causou a ele e a outros. Embora ela esteja cheia de felicidade, ele se agita e rola na cama à noite, soluçando, cheio de horror e remorso, com o coração em frangalhos. Embora ela esteja cheia de bondade, parece desatenta ao ódio que corresponde à sua bondade. Embora ela seja saudável, há aqueles que estão febris e enlouquecidos pelas condições que produzem a sua saúde. Embora ela seja bela, será que já levou em consideração como é ser enrugado, infame e desprezado? E, apesar de que ela irradie sua felicidade, sua alegria e a luz de seu bem-estar, ele suplica apenas por suas orações - não para se tornar como ela.

No poema Les Hiboux [As Corujas], Baudelaire descreve a ambição de ansiar por trocar de lugar com aqueles que são mais afortunados como uma distração inútil daqueles que estão "embriagados das sombras" (BAUDELAIRE, 1993, p. 136, poema 67). A reversibilidade não é um ato da vontade, um anseio do amante para se tornar como seu anjo, ou para que ela se torne como ele. É, em vez disso, uma lição sobre as perspectivas diversas e divergentes que emergem desse relacionamento insalubre. As experiências deles são interdependentes em sua divergência.

Tampouco a reversibilidade é um exercício cognitivo da consciência reflexiva. Por exemplo, o remorso, que Baudelaire contrasta como a felicidade do "anjo", é uma condição existencial devoradora, totalmente visceral, e não um mero processo de pensamento. Em seu notável poema Spleen (II), Baudelaire retrata seu remorso com a imagem de vermes "andando sobre meus mortos mais queridos" (BAUDELAIRE, 1993, p. 146, poema 76). Eles rastejam, eles roem, eles consomem, e o processo é lento e inexorável - um fenômeno inteiramente físico.

Quase não é preciso mencionar que essa descrição do amor como reversibilidade é antirromântica. Baudelaire aponta quais horrores vêm com esse amor. Trata-se de um amor para esses animais alienados e doentios que nós nos tornamos na idade moderna. $\mathrm{O}$ amor como um ideal certamente despencou do céu e foi trazido para o nível do chão - de modo não muito 
diferente do que Merleau-Ponty pretendia no prefácio da Phénoménologie de la perception, onde ele promete colocar as essências "de volta na existência".

Baudelaire implica o leitor como estando numa relação reversível com ele desde a abertura do livro, em seu poema Au lecteur [Ao leitor]. O leitor sofre lado a lado com ele, está sofrendo na mesma época, está também limitado pelo tédio e pela alienação de sua época ${ }^{17}$.

Para ser breve, vou me restringir aqui a umas poucas palavras a respeito da reversibilidade na filosofia de Merleau-Ponty. Merleau-Ponty descreve a reversibilidade como a "verdade definitiva" (MERLEAUPONTY, 1964, p. 204). Defendo a ideia de que Merleau-Ponty se apropria da reversibilité de Baudelaire como um princípio ontológico. Ele estabelece um contraste entre ela e a oposição dialética dualista de Sartre e, em vez disso, enfatiza a relação reversível de diferenciação. A reversibilidade está no coração da ontologia de Merleau-Ponty, lado a lado com o écart, e expressa a maneira pela qual as coisas conquistam suas identidades frágeis e divergentes, por suas ações diferenciadoras entrelaçadas umas com as outras. A reversibilidade é a habilidade em princípio - nunca completa de ser outro ser. É um modo de assinalar que a identidade que nós tomamos como base para o pensamento moderno sustenta-se sobre a habilidade de compartilhar a existência por meio de ações diferenciadoras.

Isso também fica claro no ensaio L'Oeil et l'Esprit:

Um corpo humano está ali quando, entre o ver e o visível, entre o tocar e o tocado, entre um olho e o outro, [...] entre uma mão e a outra, entre mão e mão uma espécie de entrecruzamento [recroisement] tem lugar [...] (MERLEAU-PONTY, 1963, p. 20).

E a ênfase aqui, mais uma vez, está no acontecimento, na atividade e no processo de diferenciação. De fato, até a versão final desse ensaio, Merleau-Ponty também incluía aqui "uma imbricação, uma transgressão" imediatamente após essa passagem ${ }^{18}$. Uma bela passagem

17 Cf. BAUDELAIRE (1993, p. 4-6). Várias metáforas baudelairianas animam L'Oeil et l'Esprit. Merleau-Ponty está preocupado o tempo todo com coisas mudas, que expressam o silencioso (p. 13), o límpido (como imperfeição - o lamento de Descartes pelo fato da consciência tornar todas as coisas claras - p. 36), "philtres" (p. 35), assombrações (p. 13), febres (p. 30), sombra/crepúsculo/amanhecer, fantasmas (p. 30, 33), renversements (p. 19), sonhos/pesadelos e encarnação por toda parte. Num trabalho mais extenso, cada uma dessas metáforas poderia ser explorada em maior detalhe.

18 MERLEAU-PONTY (1963), notas, v. XIII, cf. 2a. versão datilografada. 
paralela ocorre no capítulo sobre o quiasma de Le visible et l'invisible: "Por este entrecruzamento no interior do tocar e do tangível, esses mesmos movimentos são incorporados no universo que eles interrogam [...]" (MERLEAU-PONTY, 1964, p. 176). É assim que nossos estilos divergentes de ser emergem. É assim que nós nos tornamos quem somos.

O ensaio de Merleau-Ponty L'Oeil et l'Esprit é uma bela crítica da modernidade, especialmente do mundo moderno tal como figurado pela ciência. Em vez disso, Merleau-Ponty quer que nós atentemos para a "ciência secreta" do artista (cf. MERLEAU-PONTY, 1963, p. 15). Ele faz isso mediante um inquérito fenomenológico sobre os modos e meios pelos quais o artista está afinado com o "solo do mundo sensível", o qual tem sido negligenciado em favor do "mundo esquadrinhado" do conhecimento científico (MERLEAU-PONTY, 1963, p. 12). E os temas da réversibilité e do écart, desenvolvidos a partir da réversibilité e das correspondances de Baudelaire, estão no coração da ciência secreta de Merleau-Ponty. Assim, podemos ler a abordagem de Merleau-Ponty tal como ele lê a do artista: o artista em ação, refletindo de maneira autoconsciente sobre sua práxis como artista.

Para Baudelaire, a práxis do poeta deve "conferir graça às coisas mais vis" (BAUDELAIRE, 1993, p. 168, poema 87). Ele também descreve o poeta como um "inimigo piedoso do sono", que toma em seu coração as lágrimas indiscretas da lua, "distantes do sol" (BAUDELAIRE, 1993, p. 134, poema 65). Então, o poeta é aqui um inimigo do esclarecimento alguém que segreda as coisas. Contudo, o poeta faz isso por amor.

Talvez a mais interessante analogia que Baudelaire faz a respeito da práxis do poeta esteja em seu ensaio Sobre o vinho e o haxixe, onde ele compara o poeta com um catador de lixo ${ }^{19}$ :

Olhemos um pouco mais para baixo. Contemplemos um desses seres misteriosos que vivem, por assim dizer, do excremento das grandes cidades; pois há algumas ocupações estranhas por aí. Há um número imenso delas [...]. Eis um homem cuja tarefa é catar todo o entulho produzido durante um dia na capital. Tudo que a grande cidade jogou fora, tudo que ela desperdiçou, tudo que ela desdenhou, tudo que ela

\footnotetext{
19 É interessante contrastar a visão antirromântica que Baudelaire tem do poeta como o coletor de lixo da sociedade com a visão romântica de Percy Bysshe Shelley. Cf. Shelley, Percy Bysshe, "Em defesa da poesia" (2005, p. 850): "Os poetas são os legisladores não reconhecidos do mundo". Quero expressar minha gratidão ao Sr. Jacob Riley por sugerir-me essa passagem para ajudar a exprimir o contraste entre a obra de Baudelaire e os românticos mais antigos. Um dos maiores prazeres de ensinar está em aprender com os melhores alunos.
} 
quebrou, ele cataloga e coleta. Ele consulta os arquivos da corrupção [...]. Ele faz uma seleção, escolhe astutamente: como o avarento se apodera de um tesouro, ele cata o refugo que, quando mastigado pela divindade da Indústria, se transformará em objetos de uso e divertimento [...]. Ele chega, abanando a cabeça e tropeçando nas pedras do calçamento, como aqueles jovens poetas que passam seus dias andando a esmo em busca de rimas. Ele fala consigo mesmo; ele verte sua alma para o ar gelado da noite (BAUDELAIRE, 2002, p. 8).

O poeta pode criar valor em meio à alienação da modernidade. O que pode o filósofo fazer?

A ontologia de Merleau-Ponty emergiu de suas diferenças políticas com Sartre. Ele começou a tentar desenvolver uma nova filosofia da história, a qual levou à sua exploração da natureza que, por fim, conduziu à sua ontologia nascente, que ele não foi capaz de desenvolver. Não concordo com Sartre em que a ontologia de Merleau-Ponty era uma teoria voltada contra a práxis. Creio que, ao elaborar sua ontologia em termos situados a partir do trabalho do artista, Merleau-Ponty nos fornece um ponto de partida proveitoso para levar adiante a reflexão sobre a relação entre ontologia e política. Em meu próprio trabalho, comecei a explorar o modo como uma ontologia das diferenças fornece uma base para uma crítica contundente do liberalismo ocidental. Pode ser interessante considerar a inspiração que vem de Baudelaire para constatar como a ontologia de Merleau-Ponty difere de outras na tradição fenomenológica e, assim, por que uma ontologia das diferenças é mais promissora para o pensamento político.

Heidegger assinalou que cada revelar-se é também um ocultarse. Não obstante, para Heidegger, a fenomenologia preocupa-se em trazer as coisas para a luz ${ }^{20}$. Merleau-Ponty, apoiando-se no soturno leitmotiv de Baudelaire, retrata alusivamente a fenomenologia como mais preocupada com sombras, chiaroscuro e crepúsculo. Fica claro que a fenomenologia, e não apenas o filósofo, tem uma sombra. Merleau-Ponty transformou a fenomenologia em algo muito mais radical ${ }^{21}$. Em suas notas de trabalho

${ }^{20}$ Heidegger, § 7, como é bem sabido, descobre as origens da fenomenologia em phó - luz.

21 Para mim, parece claro que ele esteve consciente dessa radicalização ao longo de toda a sua carreira. Talvez isso esteja mais claro no prefácio a Phénomenologie de la perception (onde ele contrasta sua própria orientação com a de Husserl), no ensaio L'Homme et l'adversité, em Signes (onde ele contrasta a fenomenologia como movimento com a fenomenologia como método), e nas notas de trabalho para Le visible et l'invisible (onde ele contrasta seus novos insights com seu trabalho anterior). 
para L'Oiel et l'Esprit, Merleau-Ponty escreveu que era essencial radicalizar a noção de luz "para fazer da obra de arte uma Seinsgeschichte"22. Meus amigos, é a escuridão que nos convoca a refletir.

É ao afastar-se do modelo da fenomenologia como uma ciência das ciências que Merleau-Ponty se engaja em sua crítica da modernidade. Ou, para dizê-lo de outra maneira, sua crítica da ciência e a valorização do artista abrem espaço para que possamos conceber a fenomenologia como uma arte, em vez de como uma ciência, com isso transplantando a fenomenologia de volta ao rico solo do mundo sensível - o mundo da experiência vivida.

A fenomenologia concebeu, originalmente, sua sabedoria como fornecendo uma ciência das ciências. Não pode haver uma ciência da sabedoria. Pode haver uma arte da sabedoria, pois, certamente, há sabedoria na arte.

\section{A arte da crítica fenomenológica}

Pois então: qual seria o custo para o criticismo político, se ele fosse abordado como uma arte, em vez de como uma ciência? Nós propomos que há um estilo de pensamento que é bastante inoportuno - e, portanto, muito oportuno, em outro sentido. Isto é, nós propomos que se conceba uma arte política, em vez de uma ciência política - uma arte da crítica política, em vez de uma crítica científica. Nós propomos uma arte política que seja intrinsecamente crítica e distintivamente fenomenológica.

Os papéis da epoché e da redução na fenomenologia variariam ao passarmos de uma fenomenologia como ciência para uma fenomenologia como arte. Na epoché, há um colocar-se fora do jogo, um colocar-se entre parênteses ou colchetes, pelo qual a fenomenologia dá um passo atrás - mas nunca um passo para fora do mundo da experiência vivida. Embora Husserl repetidamente afirmasse que, em sua visão da fenomenologia como uma ciência das ciências, nós não renunciamos ao mundo da experiência vivida, não estou convencido que ele teve êxito nisso. Contra Husserl, a compreensão que nós obtemos do mundo em que vivemos por meio da redução fenomenológica não pode reivindicar nenhum sentido de pureza ou status eidético. Penso que precisamos, ao contrário, seguir a orientação de Merleau-Ponty, na qual percebemos a

${ }^{22}$ Cf. MERLEAU-PONTY (notas a L'Oeil et l'esprit, v. XIII, p. 148). 
tarefa da fenomenologia como sendo a de buscar um conhecimento contingente pelo engajamento, e não por uma fundamentação apodítica.

Lembremos que Merleau-Ponty, como é bem sabido, afastase de Husserl na Introdução à sua Fenomenologia da Percepção, quando faz duas audaciosas proclamações: 1) "a única coisa que podemos aprender da redução fenomenológica é que nenhuma redução completa é possível" (MERLEAU-PONTY, 1945); e 2) "nosso objetivo é pôr as essências de volta na existência" (MERLEAU-PONTY, 1945). A primeira diz que, como nunca podemos completar a epoché, a redução fenomenológica correspondente nunca será completa - e, por isso, sempre questiona a si mesma. Esta é a base da crítica política, já que toda interpretação está implicada como sujeita à crítica. Não é apenas que isso seja impossível na prática: sequer deveria ser nosso ideal remover as vicissitudes da experiência e da existência humana. Pois a existência humana purificada da contingência não é mais uma existência humana. Como Merleau-Ponty insistiu naquele mesmo texto, estamos "condenados ao sentido" (MERLEAU-PONTY, 1945), e esse sentido nunca é puro. Ele está sempre aberto à interpretação e, por isso, está sempre aberto à crítica.

Merleau-Ponty não descreveu explicitamente sua nova orientação na fenomenologia como uma arte, opondo-a à ciência da maneira como estou sugerindo. Mas penso que é apropriado estender seu pensamento nessa direção e, de fato, estou me apoiando para tanto em sua análise da arte e da ciência em seu ensaio final, L'oeil et l'esprit. O argumento do ensaio, em geral, parece ser que a arte, mais do que a ciência, revela verdades fundamentais sobre a percepção do mundo. A ciência pretende possuir uma verdade objetiva a respeito do mundo, enquanto que a arte é relegada a uma mera imitação subjetiva dele. Merleau-Ponty claramente discorda disso. A primeira linha do ensaio deixa isso claro: "A ciência compreende o mundo à custa de não mais viver nele" (MERLEAU-PONTY, 1963). O cientista esclarecido admite que, em qualquer investigação científica, há sempre contingência, mas isso é visto apenas como um erro que limita nossa busca pelo ideal objetivo. O melhor caminho é reconhecer que esse "ficar aquém" não é algo a ser superado na rota para um ideal objetivo. Ao contrário, é esse tipo de contingência que fornece os meios para toda compreensão dos fenômenos. Um conhecimento puro e objetivo do mundo não é apenas impossível de atingir: essa é uma meta que desvia nossa atenção do mundo que desejamos compreender - o mundo no qual vivemos. 
A ciência busca a objetividade pura com seu "passo atrás" teórico com relação à experiência, enquanto que a arte oferece uma forma completamente distinta de transcendência. A arte nos desengaja a fim de permitir que nos engajemos de uma nova maneira. Não temos tempo de examinar isso em detalhe, mas pode-se imediatamente pensar em vários exemplos dessa forma de epoché em ação: assistir um filme, uma peça, uma peça musical, uma dança, contemplar uma pintura, etc. Mas essa forma de epoché é diferente do passo atrás teórico da ciência. Ela envolve uma disciplina física, não alguma atitude mental abstrata que abandona o corpo ao tentar superar suas contingências. Há um tipo diferente de transcendência envolvido na epoché estética. Kurt Vonnegut descreve isso muito bem numa recente coletânea de contos, Bagombo Snuff Box. Vonnegut descreve a transcendência envolvida em ler uma história numa revista, quando era garoto:

Imaginem que é novamente 1938. Eu tenho dezesseis anos outra vez. Chego em casa de mais um insuportável dia de aula na Escola Secundária Shortridge. Minha mãe [...] diz que há um número novo do Saturday Evening Post sobre a mesa de café. Está chovendo lá fora, e eu sou tudo menos popular. Mas não posso ligar a revista como um aparelho de TV. Eu tenho que apanhá-la, ou ela vai continuar parada ali, imóvel como uma coisa morta. Uma revista sem ajuda não tem nenhum entusiasmo. Depois que a apanho, tenho que fazer com que cento e sessenta libras de carnes e ossos adolescentes se acomodem confortavelmente numa espreguiçadeira. Mas pensem na coisa incrível que eu mesmo tenho que fazer agora. Eu ponho o cérebro para funcionar!

Esta não é nem metade da coisa. Com meu cérebro à toda, eu faço a coisa quase impossível que você está fazendo agora, caro leitor. Eu decifro os arranjos idiossincráticos, em linhas horizontais, de nada menos do que vinte e seis símbolos fonéticos, dez numerais arábicos e talvez oito sinais de pontuação, sobre uma lâmina de polpa de madeira alvejada e aplainada! Mas vejam só: enquanto estou lendo, meu pulso e minha respiração desaceleram. Meus problemas da escola desaparecem [...] (VONNEGUT JR., 1999, p. 4).

Vonnegut prossegue, descrevendo jocosamente a leitura como uma forma de meditação, e a sua própria coletânea de contos como uma coletânea de "cochilos budistas" (VONNEGUT JR., 1999, p. 5).

Gostaria de enfatizar alguns pontos nesse relato. Primeiro, que o processo envolve o corpo. O leitor se prepara para a tarefa acomodandose numa cadeira. A respiração e o pulso desaceleram. Uma atitude tem 
que ser assumida pelo corpo, porque é o corpo que segura a história e a decifra. $\mathrm{O}$ corpo atinge a transcendência nessa apreciação estética.

Em segundo lugar, há uma disciplina envolvida nessa preparação. Requer muita prática ser capaz de atingir esse tipo de transcendência. Ela envolve anos de treino nas habilidades linguísticas, mas também na expectativa de que há algo de valor em engajar-se nesse processo. A leitura, como toda transcendência estética, é uma habilidade cultivada - um gosto adquirido. Essa disciplina tem seu próprio tipo de rigor, e esse rigor revela novos discernimentos.

Finalmente, sem apelar para qualquer sentido puro ou objetivo, há maneiras melhores e piores de atingir essa transcendência. Sem excluir a variedade de sentidos possíveis, há certamente alguns que são mais ou menos apropriados à situação.

Então: o que nos custaria se adotássemos um modelo estético da fenomenologia - e de uma crítica política fenomenológica? Nem discernimento, nem profundidade, nem verdade, nem disciplina e nem rigor. Pois há uma tremenda disciplina na arte - tanto na sua produção, quanto na sua apreciação. A arte é criatividade disciplinada.

A arte da política, então, deve envolver tanto disciplina quanto criatividade. A disciplina fornece a estrutura; a criatividade fornece o potencial para a esperança, para uma mudança radical. A crítica deve ser disciplinada, se ela é política. A polis disciplina a crítica, na medida em que manifesta o exercício espontâneo da vontade geral. De fato, a identidade da polis é implicada através de suas próprias práxis. A disciplina conduz à inteligibilidade da criatividade, que é comensurável com o acontecimento do juízo político [o aspecto criativo da práxis da crítica política]. A crítica política autêntica deve ser disciplinada, para poder ser reconhecível como radical ou criativa. Esse é o paradoxo que está no coração de toda crítica política genuína. Assim, uma crítica política fenomenológica do tipo que estou sugerindo propicia a criatividade disciplinada.

A abordagem que Merleau-Ponty faz da arte em L'oeil et l'esprit manifesta os termos, mencionados anteriormente, de sua obra ontológica do mesmo período de seu pensamento: écart e reversibilité. Pois o artista, a obra de arte e o intérprete da obra de arte estão todos inextricavelmente conectados por relações reversíveis. Suas identidades nunca são absolutas ou pressupostas, mas são reconhecíveis apenas por suas divergências. O pintor pinta com seu próprio corpo, que está implicado como aquele pintor pela emergência da obra de arte - assim como a pintura 
é identificada como aquela pintura na medida em que o artista se torna o artista que a pinta. A pintura tem um número infinito de sentidos que se desdobram diante dela. Os intérpretes que veem a pintura investem-na com um sentido novo, porque eles estão implicados como quem são por suas respostas ${ }^{23}$. É importante ver a maleabilidade de identidades divergentes nesses relacionamentos como manifestações da reversibilidade, em vez de como equívocos infelizes de sujeito e objeto. Apenas reconhecendo a divergência e a reversibilidade dessas situações, podemos desvelar suas implicações práticas. A reversibilidade evidencia o engajamento que faz com que as coisas tenham relevância. E a contingência da situação é, de novo, não algo a ser superado, mas o único meio pelo qual as coisas se tornam significativas. Os fenômenos requerem ser interpretados e nos implicam como responsáveis por nossas interpretações.

O pintor da modernidade - ou o escritor da modernidade não devem jamais renunciar às suas circunstâncias concretas para tentarem buscar algum ideal. A idealidade se manifesta apenas nesses momentos contingentes. Essas contingências não são um obstáculo trôpego a ser evitado; elas são nosso único meio de criar idealidade. E o pintor ou o poeta - ou o filósofo - distingue-se por ter uma visão artística ao reconhecer o ideal no mais decadente, no descartado, no refugo e nas ruínas da modernidade. É preciso engajar-se numa crítica de olhar vigilante, preocupando-se com aquilo que a sociedade destrói.

Retornemos brevemente a Baudelaire - que, como vimos, sob diversos aspectos, não está assim tão distante de Merleau-Ponty. Seu ensaio $O$ pintor da vida moderna é, ao mesmo tempo, homenagem ao artista, Constantin Guys, e também uma abordagem do papel do artista na sociedade moderna decadente - daí que seja também indiretamente autobiográfico. O ensaio de Baudelaire não é apenas um exemplo de

${ }^{23}$ É sempre interessante comparar o pensamento inicial e tardio de Merleau-Ponty. Somos lembrados de um de seus primeiros ensaios dos anos 40, Marxismo e filosofia, no qual Merleau-Ponty descreve os agentes históricos como "produtores-produtos". Cf. MERLEAUPONTY (1996, p. 163): "Pela primeira vez, desde Hegel, reflete-se não sobre a subjetividade, mas sobre a intersubjetividade". De modo similar, isso explica como, na mesma passagem, Merleau-Ponty fala dessa intersubjetividade como o lugar onde a necessidade histórica "podese transformar em liberdade concreta". Recordemos também que, na Fenomenologia da percepção, Merleau-Ponty descreveu como nossas ações transformam contingência em necessidade. A combinação dessas passagens leva-nos a considerar algo como a situação reversível que estou apresentando aqui. 
práxis, mas também de parapráxis, na medida em que seu trabalho envolve uma projeção de sua compreensão das virtudes e vícios relacionados ao papel do artista moderno. A análise da obra de Guy revela a compreensão própria que Baudelaire tem da obra, como um artista que a considera por meio de seu próprio trabalho artístico.

Baudelaire descreve Guys como um "homem do mundo" que não está à vontade no mundo. Guys "é um 'Eu' com um insaciável apetite pelo 'não-Eu', a cada instante apresentando-o e explicando-o em imagens mais vivas do que a própria vida..." (BAUDELAIRE, 1995, p. 10). Guys tinha um olhar aguçado para captar a vitalidade das circunstâncias e, assim, transmitir "os direitos e privilégios oferecidos pela circunstância" (BAUDELAIRE, 1995, p. 14) ${ }^{24}$. Se já não tivesse ficado claro que Baudelaire está refletindo sobre sua própria posição como um artista engajado na crítica da modernidade, isso ficaria óbvio quando ele elogia Guys por ser capaz de "extrair da moda qualquer elemento que ela possa conter de poesia da história" (BAUDELAIRE, 1995, p. 12). Ele elogia Guys por ser "audaz e imaginativo ao captar a nobreza onde quer que esta se encontre, mesmo que seja no lodo" (BAUDELAIRE, 1995, p. 38). E observa que, na arte, se encontra "a beleza especial do mal, o belo em meio ao horror" e uma "fecundidade moral" que o artista moderno cria para questionar os costumes de sua época (BAUDELAIRE, 1995, p. 38). Uma passagem final desse refinado ensaio bastará para indicar o papel crítico que Baudelaire considera que Guys - e ele próprio - estão desempenhando na sociedade moderna:

Ele perseguiu por toda a parte a beleza fugidia e passageira da vida atual, o caráter distintivo daquela qualidade que nós chamamos 'modernidade'. Frequentemente estranho, violento e excessivo, ele foi capaz de concentrar em seus desenhos o buquê acre ou inebriante do vinho da vida (BAUDELAIRE, 1995, p. 41).

Poderia ser interessante fazer uma investigação histórica exaustiva da influência direta de Baudelaire sobre a obra de Merleau-Ponty. Este seria um estudo diferente. Para nossos propósitos, coloquemos

\footnotetext{
${ }^{24}$ Isso nos recorda a crítica de Merleau-Ponty, numa carta a Sartre, endereçada aos pronunciamentos precipitados deste sobre todo e qualquer acontecimento, como que do ponto de vista do fim da história - isolando o momento da história e negando "o direito à retificação que é intrínseco a cada acontecimento”.
} 
simplesmente entre parênteses a questão histórica da causalidade e examinemos seus casos como paralelos. Pensemos na situação de Baudelaire no âmbito da arte, onde ele fornece uma crítica das artes e da sociedade moderna. Pensemos igualmente na situação de Merleau-Ponty no âmbito da fenomenologia, onde ele fornece uma crítica da fenomenologia e da sociedade moderna ${ }^{25}$. A convergência dessas linhas paralelas, como numa pintura, é uma questão de perspectiva. Isto é, a melhor maneira de indicar profundidade ao retratar duas linhas infinitamente paralelas, como os trilhos de uma estrada de ferro, é apresentar sua convergência. Assim, cultivemos a convergência dessas paralelas no aqui e agora de nossa própria situação no âmbito da modernidade.

É importante lembrar que, como Merleau-Ponty assinalou em sua análise da pintura, a profundidade não é uma dimensão subordinada ou incidental, mas a dimensão primária. Da mesma forma, a profundidade histórica que emerge aqui e agora para nós, ao considerarmos a situação de Baudelaire e de Merleau-Ponty como críticos, não é um erro do historicismo, mas está no coração de uma compreensão fundamental dos acontecimentos e da própria esperança que temos hoje de exercer uma crítica. Merleau-Ponty nos oferece um indício dessa dimensão acontecimental da história e de seu valor prático em $O$ olho e o espírito, embora ele não a explore com detalhes:

Há, na carne da contingência, uma estrutura do acontecimento e uma virtude peculiar ao cenário. Estas não impedem a pluralidade das interpretações, mas, de fato, são as razões mais profundas para essa pluralidade. Elas fazem do acontecimento um tema durável da vida histórica e têm direito a um status filosófico (MERLEAU-PONTY, 1963, p. 61-62).

Mais uma vez, a profundidade histórica não é, de forma alguma, ilusória, mas sim a estrutura acontecimental dos fenômenos históricos. Essa profundidade é o que permite que a história importe. É, literalmente, a feitura das diferenças que "faz diferença" para nós. Além disso, a profundidade histórica nos implica como agentes históricos responsáveis

\footnotetext{
${ }_{25}$ Examinei a filosofia política de Merleau-Ponty e, especialmente, sua relação com o marxismo em muitos de meus trabalhos. Essa discussão é bastante relevante aqui, mas não temos tempo para desenvolvê-la no contexto deste ensaio.
} 
pelo sentido de nossa situação histórica - e responsáveis por respostas criativas dentro de nossas situações históricas. E essas respostas, como quaisquer interpretações, requerem crítica.

É tendo isso em mente que eu condeno a mentalidade estreita e o dogmatismo dos atuais líderes de meu país. Eles se esforçam por absolver-se da crítica para salvaguardar seus ideais deturpados. Há algo de fundamentalmente irônico em que nosso presidente diga que "apenas a história julgará minhas ações", como se a história estivesse muito distante. Mas a história, que propicia a possibilidade da crítica, está viva, aqui e agora - não aquela abstração idealista que o presidente Bush invocou, semelhante ao que Merleau-Ponty chamou de uma "monstruosidade hegeliana". E assim, para fazer uma aplicação prática dessa noção de profundidade histórica intrínseca à crítica política genuína, eu digo: "PROFUNDIDADE (DEPTH) AO PRESIDENTE GEORGE BUSH! PROFUNDIDADE AO VICE-PRESIDENTE DICK CHENEY! PROFUNDIDADE À SUA AGENDA IMPERIALISTA!". Eles realmente precisam atentar para a profundidade histórica de se engajarem no interior da história, em vez de apelarem para uma história idealista e abstrata para prevenir-se da crítica. Mas, em minha opinião, é improvável que isso aconteça. Por outro lado, o presidente Bush pode já ter o seu desejo realizado, mesmo se ele é incapaz de reconhecê-lo: a história já está julgando a sua administração. Disso nós podemos ter certeza.

Mas não fiquemos felizes demais com a nossa condenação. Nosso engajamento específico dentro da história nos implica como coloniais. As próprias linguagens que utilizamos nos marcam como colonizados e colonizadores $^{26}$. Nossas intenções de nos engajarmos na crítica política genuína não são capazes de nos despojar de nossas heranças imperiais. Esse pretexto é o erro que os liberais dos Estados Unidos algumas vezes adotam para se sentirem bem com relação ao trabalho crítico muito limitado que fazem, descrevendo-se como esquerdistas quando são, quando muito, centristas vulgares - uma orientação política que é mais ruborizada do que vermelha.

\footnotetext{
${ }_{26}$ Por favor, não tomem essa discussão fenomenológica como uma proclamação impertinente a respeito da política brasileira. Eu reconheço que, hoje em dia, poder-se-ia tender a vê-la desse modo, quando alguém vindo dos Estados Unidos começa a falar sobre política. Tampouco pretendo sugerir que a política brasileira deva voltar-se unicamente para os teóricos franceses, para possibilitar uma crítica genuína. Columbia poderá estar logo se voltando para a França em busca de liderança [Mme. Bettancourt], mas o Brasil tem a sua situação própria.
} 
Nos dias de hoje, devemos evitar a fascinação dos falsos ideais da crítica política científica. Devemos nos engajar na arte da crítica política para alcançar nossa liberdade. A liberdade política é a liberdade da polis e só pode ser alcançada pelo trabalho colaborativo dentro da polis, não importa quão vil ou decadente esta possa ser. Fornecemos descrições fenomenológicas de um mundo inumano na esperança de transformá-lo. Nosso trabalho e nossa esperança não repousam em nenhum outro lugar, a não ser na crítica do imperialismo em meio às ruínas dos impérios. Esta é a práxis do filósofo da vida moderna.

\section{REFERÊNCIAS}

BAUDELAIRE, C. The flowers of evil. Tradução de MacGowan. Oxford: Oxford University Press, 1993.

The painter of modern life. London: Phaidon Press, 1995.

. On wine and hashish. London: Hesperus Classics, 2002.

CARBONE, M. La visibilité de l'invisible. Hildesheim: Olms Verlag, 2001.

CULLER, J. Baudelaire's Correspondances: intertextuality and interpretation. In: PENDERGAST, C. (Org.). Nineteenth Century French Poetry. Cambridge: Cambridge University Press, 1990.

MARTIN, C. D. Beyond romance. Albany: State University of New York Press, 2004.

MERLEAU-PONTY, M. Phénomenologie de la perception. Paris: Gallimard, 1945.

L'Oeil et l'esprit. Paris: Gallimard, 1963.

. Le visible et l'invisible. Paris: Gallimard, 1964.

Sens et non-sens. Paris: Gallimard, 1996.

RICHARDSON, J. Baudelaire. Nova York: S. Martin's Press, 1994.

SHELLEY, P. B. Defense of poetry. In: GREENBLATT, S.; ABRAMS, M. C. (Ed.). Norton antropology of english literature. 8th. New York: Norton, 2005.

STARKIE, E. Baudelaire. New York: New Directions, 1958.

VONNEGUT JR., K. Bagombo Snuff Box. New York: Berkeley Books, 1999. 


\section{Anexo: Dois poemas de Charles Baudelaire ${ }^{27}$}

\section{Correspondances}

La Nature est um temple où de vivants piliers Laissent parfois sortir de confuses paroles; L'homme y passe à travers de forêts de symboles Qui l'observent avec des regards familiers.

Comme de longs échos qui de loin se confondent Dans une ténébreuse et profonde unité, Vaste comme la nuit et comme la clarté, Les parfums, les couleurs et les sons se répondent.

Il est des parfums frais comme des chairs d'enfants, Doux comme les hautbois, verts comme les prairies,

- Et d'autres, corrompus, riches et triomphants,

Ayant l'expansion des choses infinies, Comme l'ambre, le musc, le benjoin et l'encens, Qui chantent les transports de de l'esprit et des senses.

\section{Correspondências}

A Natureza é um templo, em que pilares vivos Deixam às vezes escapar palavras confusas;

O homem aí passa, através de florestas de símbolos, Que o observam com miradas familiares.

Como ecos longos que de longe se confundem Em uma tenebrosa e profunda unidade, Vasta como a noite e como a claridade, Os perfumes, as cores e os sons se respondem.

27 Nota do Tradutor: O autor apresenta, no original, suas próprias traduções literais desses poemas, uma vez que a tradução poética pode deixar escapar certas nuanças de sentido que são imprescindíveis para sua interpretação filosófica. No mesmo espírito, apresento aqui traduções igualmente literais em português. 
Há perfumes frescos como carnes de crianças, Doces como oboés, verdes como pradarias,

- E outros corrompidos, ricos e triunfantes,

Tendo a expansão das coisas infinitas,

Como o âmbar, o almíscar, o benjoim e o incenso,

Que cantam a exaltação do espírito e dos sentidos.

\section{Reversibilité}

Ange plein de gaité, connaissez-vous l'angoisse, La honte, les remords, les sanglots, les ennuis, Et les vagues terreurs de ces affreuses nuits Qui compriment le coeur comme um papier qu'on froisse? Ange plein de gaité, connaissez-vous l'angoisse?

Ange plein de bonté, connaissez-vous la haine, Les poings crispés dans l'ombre et les larmes de fiel, Quand la Vengeance bat son infernal rappel, Et de nos facultés se fait le capitaine?

Ange plein de bonté, connaissez-vous la haine?

Ange plein de santé, connaissez-vous les Fièvres, Qui, le long des grands murs de l'hospice blafard, Comme des exilés, s'en vont d'un pied traînard, Cherchant le soleil rare et remuant les lèvres? Ange plein de santé, connaissez-vous les Fièvres?

Ange plein de beauté, connaissez-vous les rides, Et la peur de vieillir, et ce hideux tourment De lire la secrète horreur du dévouement Dans des yeux où longtemps burent nos yeux avides? Ange plein de beauté, connaissez-vous les rides?

Ange plein de bonheur, de joie et de lumières, David mourant aurait demandé la santé Aux émanations de ton corps enchanté; Mais de toi je n'implore, ange, que tes prières, Ange plein de bonheur, de joie et de lumières! 


\section{Reversibilidade}

Anjo cheio de alegria, conheces a angústia, a vergonha, o remorso, os soluços, o tédio, e os vagos terrores dessas noites atrozes que comprimem o coração como um papel que se amassa? Anjo cheio de alegria, conheces a angústia?

Anjo cheio de bondade, conheces o ódio, os punhos crispados na sombra e as lágrimas de fel, quando a Vingança soa sua convocação infernal e se faz senhora de nossas faculdades?

Anjo cheio de bondade, conheces o ódio?

Anjo cheio de saúde, conheces as Febres, Que, ao longo das paredes desbotadas do hospício, vão arrastando os pés, como exiladas, movendo os lábios e buscando o sol escasso? Anjo cheio de saúde, conheces as Febres?

Anjo cheio de beleza, conheces as rugas e o medo de envelhecer, e esse hediondo tormento de ler o secreto horror do sacrifício nos olhos em que longamente beberam nossos olhos ávidos? Anjo cheio de beleza, conheces as rugas?

Anjo cheio de ventura, de luz e de alegria, David agonizante teria suplicado por saúde às emanações de teu corpo encantado; mas de ti eu só imploro, anjo, por tuas preces, anjo cheio de ventura, de luz e de alegria. 